\title{
Singularidad y técnica industrial en la producción artística de Alexander Rodchenko
}

\section{Artículo de reflexión}

\section{Enrique Andrés Morales Garrido}

Pontificia Universidad Católica de Valparaíso enrique.morales@pucv.cl

Recibido el: $12 / 03 / 2020$

Aceptado el: 03/03/2021

Cómo citar este artículo: Morales Garrido, E. A. (2021). Singularidad y técnica industrial en la producción artística de Alexander Rodchenko. Calle 14: revista de investigación en el campo del arte. 16(30), pp.408-417. https://doi.org/10.14483/21450706.18309

Autor

Este artículo surge como continuación de un trabajo de investigación sobre las vanguardias y, en especial, del constructivismo soviético agrupado en la revista LEF.

\section{(c) (1)}

https://creativecommons.org/licenses/by/4.0/deed.es 


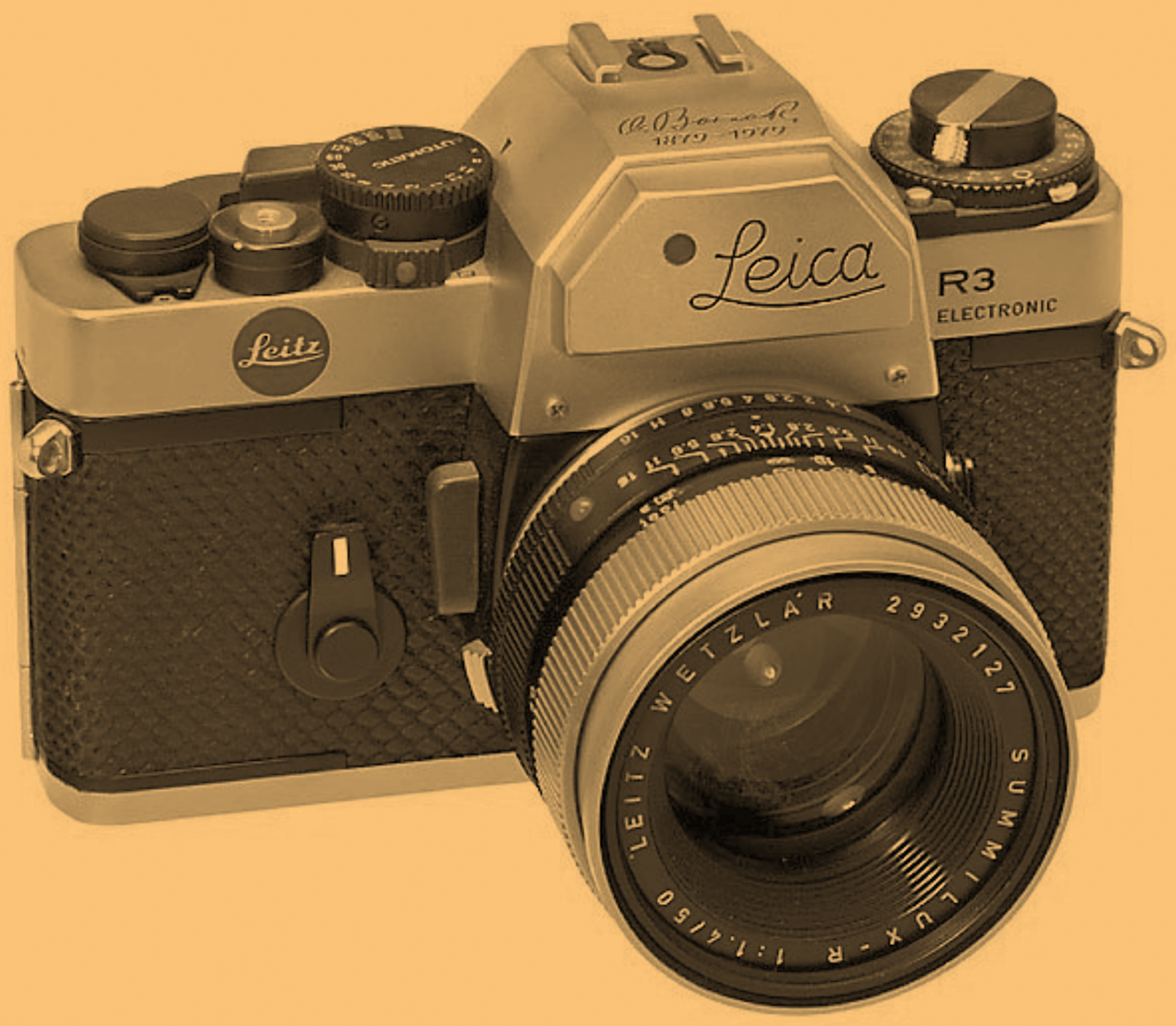


Singularidad y técnica industrial en la producción artística de Alexander Rodchenko

\begin{abstract}
Resumen
El artículo se pregunta por el rol de la singularidad artística en la teoría y práctica de Alexander Rodchenko. Para ello se analizan e interpretan tres textos y una fotografía del período constructivista del artista. Primero, se revisan cartas de su estadía en París, cuando ya ha renunciado a la pintura y explora la fotografía; segundo, un artículo publicado en la revista LEF, donde diferencia el ideal esteticista de la pintura del trabajo fotográfico; y, finalmente, a una autobiografía donde traza un lazo desde el arte técnico hasta la experiencia infantil de la magia y el espectáculo. La fotografía es la famosa Muchacha con una Leica. Los documentos parecen evidenciar una concepción del arte moderno basada en la apropiación del desarrollo industrial, pero que reafirma el gesto particular de la experiencia artística.
\end{abstract}

Palabras claves

Constructivismo; fotografía, LEF; singularidad; técnica

Singularity and industrial technique in the artistic production of Alexander Rodchenko

\begin{abstract}
This article asks about the role of artistic singularity in Alexander Rodchenko's theory and practice. For this purpose, three texts and a photograph of the artist's constructivist period are analyzed and interpreted. Firstly, letters from his stay in Paris are reviewed, when he had already given up painting and explores photography; then, we examine an article published in the LEF magazine, where he differentiates the aestheticist ideal of painting photographic work; and, finally, an autobiography where he traces a link from technical art to children's experience of magic and spectacle. The photograph is the famous The Girl with the Leica. The documents seem to show a conception of modern art based on the appropriation of industrial development, but that reaffirms the particular gesture of the artistic experience.
\end{abstract}

\title{
Keywords
}

Constructivism; photography, LEF; singularity; technique

Singularité et technique industrielle dans la production artistique d'Alexander Rodchenko

\section{Résumé}

L'article s'interroge sur le rôle de la singularité artistique dans la théorie et la pratique d'Alexander Rodchenko. A cet effet, trois textes et une photographie de la période constructiviste de l'artiste sont analysés et interprétés. Dans un premier temps, des lettres de son séjour à Paris sont passées en revue, alors qu'il avait déjà renoncé à la peinture et explorait la photographie ; puis, nous examinons un article publié dans le magazine LEF, où il différencie l'idéal esthétiste de la peinture du travail photographique ; et, enfin, l'autobiographie où il trace un lien entre l'art technique et l'expérience enfantine de la magie et du spectacle. La photographie est la célèbre La Fille au Leica. Les documents semblent montrer une conception de l'art moderne fondée sur l'appropriation du développement industriel, mais qui réaffirme le geste particulier de l'expérience artistique.

\section{Mots clés}

Constructivisme ; photographie ; LEF ; singularité ; technique 


\section{Resumo}

O artigo se pergunta pelo papel da singularidade artística na teoria e prática de Alexander Rodchenko. Para isso, se analisam e interpretam três textos e uma fotografia do período construtivista do artista. Primeiro, se revisam cartas de sua estadia em Paris, quando abandou a pintura e explora a fotografia; segundo, um artigo publicado na revista LEF, onde diferencia o ideal esteticista da pintura do trabalho fotográfico; e, finalmente, a uma autobiografia, onde traça um laço a partir da arte técnica até a experiência infantil da mágica e o espetáculo. A fotografia é a famosa Muchacha com una Leica. Os documentos parecem evidenciar uma concepção de arte moderna baseada na apropriação do desenvolvimento industrial, mas que reafirma o gesto particular da experiência artística.

\section{Palavras chave}

Construtivismo; fotografia, LEF; singularidade; técnica

\section{Maillallachiska}

Kai kilkaipi kikin tapuchiriku kai runa Alexander Rodchenko suti pai munaku kawangapa allilla kimsa kilkaskata pangapi ruraska ñugpa iuiarispa imasami challaska pasanga Paris suti Llagtapi kausaura kunaura ña sakiska kai ruraikuna kallariska sug paita sumaska iskai kilkaipi churaska LEF, kaipi muna parlanga pai wawa kaura kausaska llukanii chasallata sug suma rurai sipas warmi. Chasalla apachi ñugpamanda kunankama pai pasaskata sug kunata iachachingapa.

\section{Rimangapa Ministidukuna}

Churai utka iachaikungapa; pangapa ruraska; LEF chasa suti iachaikudiru; kausadiru kawaspa; nuka ruraska sumaglla 


\section{Introducción}

Esta reflexión sobre la poética del artista soviético Alexander Rodchenko se enmarca en una más amplia acerca del fenómeno de las vanguardias europeas y cómo pensaron el fenómeno de la industrialización en la producción artística. Ello supuso, por una parte, enfrentar una crisis del sistema de bellas artes $y$, por otra, asumir la oportunidad de generar otra experiencia del arte $y$, posiblemente, de la vida. Este problema entre arte y la vida industrial ha sido largamente abordado por Walter Benjamin $y$, en general, por la escuela de Frankfurt. Sin embargo, el filósofo Jacques Rancière ha criticado el hecho de que Benjamin haya asumido tan rápidamente las derivaciones de las propiedades estéticas y políticas de un arte a partir de sus propiedades técnicas y que, por lo mismo, habría que pensar a la inversa:

Para que las artes mecánicas puedan dar visibilidad a las masas, o más bien al individuo anónimo, antes deben ser reconocidas como artes. Es decir, antes deben ser practicadas y reconocidas como algo distinto de las técnicas de reproducción o difusión (2002, pp. 52-53).

Si hasta comienzos del siglo veinte lo propio del arte europeo occidental había consistido en su vínculo con el individuo como dimensión material y espiritual, teniendo a la naturaleza como modelo de imitación; los artistas constructivistas y productivistas se volcaron a elaborar una concepción de lo artístico vinculada al trabajo mecanizado, la producción de objetos para la vida corriente de las masas, la moda, la publicidad, etc. El artista Alexander Rodchenko fue partidario de esta posición, que expresó en varios de los artículos y manifiestos publicados en la revista LEF. ${ }^{1}$

Sin embargo, el paso de Rodchenko a la técnica moderna no supuso simplemente el renunciar a la pintura y abrazar la fotografía, hubo también en Rodchenko un modo singular de querer practicar la industrialización en el arte. Singularidad que más que la expresión de una personalidad, constituyó un modo de producción impropia del arte de entonces. En esta inmersión en lo industrial (masivo, uniformador y repetitivo) Rodchenko sostuvo el carácter excepcional del arte, ese trato con las cosas para que no sean meras cosas o, como él mismo dice, para "hacerlas volar". Este ideal tiene varias etapas que se suceden con rapidez a partir de la revolución de 1917: comienza con su actividad como pintor que renuncia a la pintura ilusionista

1 Cfr. Rodchenko, Alexander (2018). -idea estructuras espaciales o construye objetos-, para luego sucederlo el productor de fotomontajes y pasar finalmente a ser el fotógrafo que quiere organizar de otra manera la realidad. ${ }^{2}$

\section{Cartas desde París}

Es en el momento de exploración del mundo de la fotografía que Rodchenko llega a París, para hacerse cargo de la instalación de su proyecto el Club Obrero en la Feria Internacional de Artes Decorativas e Industrias Modernas, de 1925; y, al mismo tiempo, se encarga de colaborar en la producción del pabellón soviético que tuvo un lugar relevante en dicho evento. Durante los tres meses de estadía, Rodchenko se dio tiempo para escribir cartas casi todos los días a Várvara Stepanova, a su hija y a su madre. Estas cartas fueron publicadas, a petición de él mismo, en la revista Nueva LEF, en 1927, y se transformaron en observaciones claves de la vida del París industrial de comienzos del siglo veinte, que serán decisivas en la dirección que tomará su trabajo posterior. En ellas, se cruzan los mensajes de amor y opiniones sobre el arte y la revolución con las miradas a la moda masculina y femenina, la compra de cámaras, la visita a industrias de automóviles y estudios de cine, y la asistencia a espectáculos de cabaret y circos, entre otros. Ante este panorama de cosas de la industria, el ojo de Rodchenko se interesa por todo. Se ajusta a la moda de París (la que en un comienzo parece disfrutar) $y$, al mismo tiempo, sufre su desajuste de manera cada vez más evidente:

Probablemente porque todo es ajeno y ligero, como si estuviera hecho de papel; trabajan y hacen cosas buenas, pero ¿para qué? Probablemente aquí puedes trabajar en cualquier parte, pero ¿para qué sirve? Para llevar sombrero y cuello y ser igual que los demás y no distinto. (París, 2 de abril de 1925) (Rodchenko, 2009, p. 51)

En poco tiempo la vida industrial de los franceses se le aparece como un sin sentido, ya sea por el desapego que muestran hacia los objetos en su consumo como por el carácter de objeto de la mujer en

2 En 1921, Alexander Rodchenko exhibe Línea (1920), Cuadrícula (1921), y su última obra titulada: Color rojo puro, color azul puro, y color amarillo puro (1921), para la muestra $5 \times 5=25$ El carácter conclusivo de una etapa queda claramente establecido en la siguiente declaración: "Reduje la pintura a su conclusión lógica y exhibí tres telas: rojo, azul y amarillo. Afirmé: se acabó." 
la vida moderna, todo rodeado por un cierto aire de espectáculo.

El culto de la mujer como del queso azul o de las ostras, llega a tal extremo que ahora están de moda las mujeres feas, mujeres parecidas al queso podrido, con caderas estrechas y largas, sin pecho y sin dientes, con los brazos espantosamente largos y deformes, cubiertos de manchas rojas, mujeres al estilo 'Picasso', al estilo 'de los negros', mujeres al etilo 'de los enfermos', mujeres al estilo 'de la basura de la ciudad'. (París, 25 de marzo de 1925) (Rodchenko, 2009, p. 39)

Se irrita pensando en la situación de la mujer, del arte y de las cosas en este lado del mundo y siente que para redimir esta situación es necesario recurrir a Oriente, porque allí "todo es genuino y sencillo" (Rodchenko, 2009, 51). Para este artista soviético es posible aprender de Occidente y trabajar en Oriente, porque Occidente sin la técnica es solo "un montículo infecto, impotente y débil" (Rodchenko, 2009, 51). Oriente parece un lugar donde escapar también de todo este sin sentido de la producción industrial occidental: "es mejor marcharte a China y, allí, tumbarte, soñar[...]." Todo lo que [Europa] ha creado es susceptible de ser aprovechado, parece que "solo es necesario lavarlo y limpiarlo... y establecer un objetivo." (Rodchenko, 2009, 52)

Pero, en este ir y venir de la ensoñación, su fascinación por lo industrial no retrocede y sustituye al arte. Diariamente, después del trabajo en el montaje del pabellón y del Club Obrero, Rodchenko se deja llevar por la ciudad. Sale de compras, va al cine, ve El chico de Chaplin y encuentra genial la película (Rodchenko, $2009,71)$. Acude a la exposición de El salón de los independientes, pero manifiesta su decepción con los artistas expuestos: siguen haciendo pintura, sin mostrar ningún avance después de lo hecho por Picasso, Braque y Léger. (Rodchenko, 2009, 73) El distanciamiento de Rodchenko con los artistas modernos europeos se manifiesta especialmente con los pintores, como si viera en ellos que lo artístico es solo un cambio de estilo, una trampa, y eso estimulará en él un deseo de más libertad:

Hablé con Léger y me mostré presuntuoso. Soy artista... Lo que hace Léger yo lo he dejado de hacer hace mucho... Y a mí me gusta no solamente que escriban sobre mí, que me editen, que me elogien... También me gusta estar tumbado al sol y no hacer nada en absoluto... O, de repente, dedicarme al cine-foto o Dios sabe a qué... y ser un niño, olvidarlo todo... y reparar un candado, y leer a Pinkerton. ${ }^{3}$ (París, 1 de junio de 1925) (2009, p. 138)

Las cartas desde París parecen insinuarnos que el arte y la producción industrial en Francia se sostienen todavía en una concepción muy pobre de las cosas y los seres. El arte se mantiene en la tradición de la pintura sin tomar en cuenta los cambios técnicos que por todas partes invaden la vida europea; la producción industrial somete la vida a la lógica del consumo. En este mismo sentido, para Rodchenko la revolución soviética no se limita únicamente a la liberación de los trabajadores, porque, según él:

La luz de Oriente es una nueva actitud hacia el individuo, la mujer y las cosas.

Nuestros objetos en nuestras manos deben ser también iguales, también camaradas y no esclavos negros y lúgubres, como aquí.

El arte de Oriente tiene que ser nacionalizado y racionalizado. Los objetos cobrarán un sentido y se convertirán en los amigos y camaradas del hombre, y el hombre aprenderá a reír y a disfrutar y a hablar con los objetos[...]

Tiene razón Maiakovsvi en 150000 000. Los libros se desarmarán y las hojas, como una muchedumbre revolucionaria, destruirán los cerebros podridos de sus autores. (4 de mayo de 1925) (2009, p. 91)

Si, como lo reitera, en Occidente las cosas que produce la industrialización pueden llegar a ser el opio de la vida, entonces en Oriente se debe permitir hacer y apreciar las cosas verdaderas (Rodchenko, 2009, p. 105). Esta mirada limpia hacia los objetos se completa con la imagen del poema de Maiakovski, donde cada una de las hojas del libro, ahora como panfletos multitudinarios, se revelan contra la falsa idea de autor que todavía predomina en el mundo literario. ${ }^{4}$ Rodchenko rechaza el poder sobre las cosas para imponerles ideas, cada objeto es para él un sin fin de posibilidades. "Ahora entiendo que no es necesario imitar nada, sino coger las cosas y transformarlas a nuestra manera". (2009, p. 138). Este transformar 'a nuestra manera' (la comu-

3 Quizás su falta de dominio del francés, su devoción al trabajo y el querer alejarse de todo lo artístico para privilegiar su mirada de la industria, no le permitió enterarse del manifiesto surrealista lanzado un año antes por un grupo de artistas que habría acogido con buenos ojos esta ensoñación infantil.

$4 \quad$ Esto confirma que Benjamin tomó su tesis de reemplazar la idea de autor por la de productor, no solo de Brecht, sino también a partir de las ideas renovadoras de los artistas soviéticos de vanguardia. 
nista) supone también una luz propia que cae sobre las cosas y las vuelve ligeras, con la cual el hombre aprende a reír y a disfrutar y hablar con los objetos.

Por lo tanto, como se mencionó más arriba, se puede descartar en Rodchenko una mera adecuación técnica entre bellas artes y medios industriales, porque si bien existe un rechazo al arte occidental heredado, especialmente en su faceta esteticista decimonónica, el paso a la práctica del arte industrial supone un lenguaje de los aparatos que no reproduzca el de las bellas artes ni la lógica de la producción industrial; pero que sí incorpore el modo singular del arte de enfrentarse a sus objetos, una praxis artística. En la relación industrialización y revolución, Rodchenko quiere evitar el estereotipo y aboga por una praxis en que se vuelve a observar y percibir las cosas en posibilidad. De cierta manera, se reivindica el elemento mágico del arte, gracias al cual las cosas nos devuelven la mirada. En este trato abierto con sus objetos es que el artista industrial se reivindica como artista singular.

\section{Muchacha con una Leica}

De vuelta en la Unión Soviética, Rodchenko se dedica completamente a la fotografía. La búsqueda de una mirada particular en su relación con la realidad, se aleja completamente de las artes tradicionales. La próxima vez que se refiera a la pintura será en la revista Nueva $L E F$, en un artículo titulado Contra el retrato sintético en pro de la instantánea (Rodchenko, 2018). Lenin había muerto en 1924 y por supuesto que su figura fue disputada entre los artistas experimentales y los que no lo son, por medio de retratos pictóricos y fotográficos. El retrato pictórico es descrito por Rodchenko como un movimiento de síntesis guiado por el anhelo de la verdad definitiva acerca del retratado. En cambio, la captura fotográfica, con su filiación técnico científica, aspiraría solamente a entregar un momento, un instante incompleto del retratado. Por lo tanto, ninguna fotografía podría atribuirse haber conseguido dar con el carácter verdadero del retratado, como sí había sido la aspiración de la pintura. Rodchenko lo resume así:

Hace falta plantear con fuerza que desde el origen de los documentos fotográficos no se puede hablar de ningún modo de un retrato inmutable. Es más, la persona no constituye una síntesis, ella es muchas síntesis, a veces absolutamente contrapuestas -concluye. (2018, p. 61)
Esta es la base de su argumentación contra todos aquellos que intentan inmortalizar pictóricamente a Lenin. Los archivos fotográficos ya no permiten idealizar ni deformar en nombre de la eternidad.

Muéstrenme dónde, cuándo y ante cuál de estas imágenes artístico-sintéticas podemos decir: éste es el real V.I. Lenin.

No hay. Y no habrá.

No hay ni habrá porque se tiene un archivo fotográfico, y este archivo de tomas instantáneas no permite a nadie idealizar y deformar a Lenin. (Rodchenko, 2018, p. 60)

Esta escisión que plantea Rodchenko —entre retrato pictórico e instantánea fotográfica- deja ver otra mayor en el interior del campo artístico soviético: por una parte, aquellos que deseaban producir desde el lenguaje propio de cada aparato; y, por otra, los que preferían seguir usando las formas tradicionales del arte, incluso en la fotografía y el cine: fotografías que parecen pinturas y películas que ponen en escena obras de teatro.

Para comprender su posición, veamos una fotografía que toma cuatro años después de ese artículo: Muchacha con una Leica ${ }^{5}$. A Rodchenko no le agradaba hacer retratos de mujeres como objeto de deseo, en vez de ello, sus imágenes femeninas surgen marcadas normalmente por sentimientos de camaradería y compañerismo (Tupitsyn, 2003, p. 178). Su modo de trabajo consistía en crear secuencias de su objeto, explorándolo desde diferentes posiciones (Lodder, 2014, p. 3). Como ya se sabe, le gustaba hacer tomas desde abajo y desde arriba, emplear ángulos oblicuos, lo que le permitía jugar con las partes de una fotografía como si fueran elementos abstractos en un plano bidimensional. Pero Muchacha con una Leica es, entre todas sus fotografías, una excepción a la primera de estas reglas: pertenece a una época en que Rodchenko mantuvo un romance con Eugenia Lemberg, una ex estudiante de los Vjutemas ${ }^{6}$. En ella se pueden observar rasgos poco usuales en su fotografía: por ejemplo, según una lectura psicoanalítica (Tupitsyn, 2003, p. 179), es posible observar cómo es reemplazado el espacio público por el espacio íntimo, y las sombras recorren el cuerpo del retratado. En un ángulo más formal, el crítico y escritor Victor Shklovski observó que en la foto del parque Gorky, Rodchenko oscurece el rostro y los ángulos de Eugenia Lemberg

5 La fotografía se puede ver en: https://tinyurl.com/2df4ymd7

6 Talleres de Enseñanza Superior del Arte y de la Técnica. 
mediante el uso de la luz y la sombra, para distorsionar la relación espacial en la fotografía y la del fotógrafo con el espectador, volviéndola infamiliar, haciéndola difícil de percibir en su forma habitual (Lodder, 2014, p. 3). Si bien en este caso Rodchenko tiene la necesidad de volver la fotografía un acto erótico, que logra inscribirse en la distorsión espacial, mantiene su voluntad de no querer capturar a la amada bajo el ojo del esencialismo estético. En vez de ello, expresa su amor por ella de un modo propio: con el predominio de la sombra crea una atmósfera de calma, divide el espacio con una grilla de luz semejando una prisión, enmarca con sombras los ojos y deja asomar apenas el labio, la eleva, la inclina a la izquierda y, entonces, el vértigo. De cierta manera, nada en Eugenia aparece como definitivo: ni su rostro, ni su pose, ni su oficio, ni su estatuto de amante. El rostro aparece fragmentado, la pose está distorsionada por la composición y su carácter de fotógrafa en ciernes parece asomar a través del título: Muchacha con una Leica, donde Leica es también el vehículo amoroso que los vuelve semejantes e íntimos.

En definitiva, es posible observar en este ejemplo, que la tesis del retrato pictórico no anula su posibilidad en la fotografía; pero sí requiere un tratamiento circunstancial, donde lo que se intenta es no estetizar y producir un momento singular del tiempo con otra organización del espacio. O sea, para Rodchenko el problema de la fotografía no está entre la copia y el original, sino en la posibilidad de que esa fotografía sea un hecho singular, una experiencia nueva.

\section{Autobiografía}

Desaparecida la agrupación de artistas de la revista LEF, habiendo sufrido una crítica a su trabajo fotográfico como excesivamente pictórico y formalista, y en el comienzo de la segunda guerra mundial, Rodchenko escribe en tercera persona un texto autobiográfico de cinco páginas titulada Blanco y Negro (2009, pp. 161-165). Ahí se evidencia la importancia que tiene lo mágico para este artista en el ámbito de su experiencia y visión del arte moderno. El texto narra cómo vivió gran parte de su infancia en la parte alta de un teatro de San Petersburgo, y solo le bastaba bajar las escaleras para acceder al escenario. Conocía todos los rincones del teatro como su casa. Cuando la sala se encuentra vacía, gracias a su imaginación, "este niño se sienta en el escenario y comienza a hacer cosas increíbles, crea combinaciones de colores y luces que aparecen y desaparecen, y resurge volando en el aire plagado de sonidos y creaturas extrañas" (Rodchenko, 2009, p. 162).

Cuenta también que cuando llega la revolución, se dedica a organizar círculos de creadores, exposiciones, enseña composición en los Talleres Superiores Artísticos y Técnicos del Estado (VJUTEMAS). Como él mismo dice: "estaba lleno de ideas y proyectos, y era feliz con tantas posibilidades y perspectivas. Literalmente, volaba." (2009, p. 164)

Viene entonces la etapa de los montajes teatrales, llenos de colores y también del blanco y negro, con alusiones al futuro o a lo fantástico. Realiza los primeros fotomontajes de la Unión Soviética y son la base de su teoría productiva: realizar experimentos con materia real. El recién creado planetario de Moscú,

[U]na fantasía hecha realidad[...] le hizo buscar incesantemente una realidad fantástica. $\mathrm{O}$ bien, buscar la fantasía dentro de lo real. Y mostrar un mundo que la gente aún no ha aprendido a ver, nuevas perspectivas, nuevos puntos de vista, nuevas formas. Y así llegó la fotografía..." (Rodchenko, 2009, p. 164)

Y también una Leica negra, con la cual "el mundo familiar y conocido será mostrado con enfoques nuevos." (Rodchenko, 2009, p. 164) Ahora hará propaganda con la fotografía mostrará todo lo nuevo, joven y original. "Pero allí... el vuelo se cortó" (Rodchenko, 2009, p. 165). En este momento, Rodchenko se detiene en la crítica que le había caído encima por el supuesto formalismo de su fotografía acusándolo de imitar a los fotógrafos occidentales.

La crítica le cayó con toda su fuerza.

Por el formalismo, por los enfoques, etc.

De nuevo se hizo un niño solitario.

(2009, p. 165)

Pero en vez de distanciarse del vocabulario que compartía con sus compañeros occidentales, insiste en él. Y las razones, me parece, se encuentran en este fragmento de la autobiografía:

¿Acaso no le hacen falta al país del Socialismo los ventrílocuos, los prestidigitadores $Y$ los malabaristas? ¿alfombras, fuegos de artificio, planetarios, flores, caleidoscopios? Cansado, se preparó para la exposición de los maestros de la fotografía soviética. 
Literalmente, no sabe que enviar a la exposición. Otra vez lo van a criticar y censurar.

Más de una vez pensó: ¿vale la pena participar?

Y de repente: !el éxito!

Ahí está. Una salva los aplausos. Se levantó y voló...

De nuevo se abrieron las increíbles posibilidades del acto creador. La sala llena a rebosar.

En el precipicio negro resultan ser todos personas conocidas y cercanas.

$Y$ piden: !volar!

Ellos le piden a aquel muchacho experimentos y fantasías. Todo aquello con lo que él soñaba... (Rodchenko, 2009, p. 165)

Creo que con este último fragmento de su diario, puesto en conjunción con las cartas de París y su concepción de la fotografía, es posible pensar que la producción artística de Rodchenko estuvo marcada por el anhelo de una obra que hiciera volar (al artista, en primer lugar, y al público también) gracias a lo que podríamos llamar una 'fantasía acrobática'. El artista como un malabarista, acróbata y mago. Todo lo cual por supuesto se sustenta en los juegos de la infancia que parecen no haberlo abandonado nunca. Pero, ahora, el niño-adulto ha descubierto que es posible cuestionar la técnica desde el punto de vista de la magia y que la magia es una cuestión técnica.

Como un malabarista, su etapa pictórica y de producción de objetos y fotomontajes está llena de objetos y personas que parecieran volar o sostenerse autónomamente en el espacio. Gran parte de su fotografía se caracteriza también por un vínculo estrecho entre la deformación del espacio y las poses acrobáticas que requiere para hacer sus tomas desde arriba o desde abajo. Hay varias imágenes que lo muestran en cornisas de edificios, en bordes de barandas, en rocas, etc. Esto también se agrega a su afán por la manera de distorsionar el espacio visual (su truco), creando un lugar completamente otro con el real. Pero, sobre todo, por su deseo como ser humano de recuperar el poder de hacer cualquier cosa.

En síntesis, la propuesta artística de Rodchenko, además de abrazar la técnica industrial, solicita con ella el carácter mágico que ha estado siempre presente en el espectáculo artístico, que es lo singular de la experiencia artística en un mundo altamente racionalizado.

\section{Referencias}

Benjamin, Walter (2010). La obra de arte en la época de su reproducción mecánica. Casimiro Libros: Madrid, España.

Lodder, Christina (2014). "Revolutionary photography". In Mitra Abbaspour, Lee Ann Dafner, And Maria Morris Hambourg (comp.) Object: Photo. Modern Photographs: The Tomas Walter Collection 1909-1949. An Online Project of The Museum of Modern Art. New York: The Museum of Modern Art, 2014.

Rancière, Jacques (2002). La división de lo sensible. Estética y política. Centro de Arte de Salamanca: Salamanca, España.

Rodchenko, Alexander (2018). “Contra el retrato sintético en pro de la instantánea", en Frente de Izquierda de las artes LEF iA la producción! Traducción de Carlos Henrickson. Catálogo Libros: Viña del Mar, Chile.

(2009). Cartas de París. La Fábrica editorial:

Madrid, España.

[Fotografía de Alexander Rodchenko]. (Moscú. 1932).

Tupitsyn, M. (2003). "Aleksandr Rodchenko: Woman with a Leica or 'Letters not about love.'" Journal History of Photography, Volume 27, Number 2, Summer 2003. https://doi.org/10.1080/03087298.2003.10443268 